\title{
AN EXTENDED SYSTEMS APPROACH TO CHANGE IN LABOR RELATIONS DURING THE EMERGENCE OF A NEW ECONOMY
}

\author{
Author(s) / Auteur(s) : \\ Tatiana A. MEDVEDEVA \\ Dc. Sc., Professor \\ Siberian State University of Transport \\ Faculty of World Economy and Law \\ Novosibirsk, Russia \\ tmedvedeva@mail.ru
}

\begin{abstract}
Résumé :
The emergence of a new pattern labor relations in a time of globalization and digitalization of an economy is a difficult and uncertain phenomenon, and therefore many researchers have expressed serious concern about the fate of labor and labor relations. This article explores how the forming of a network economy influences labor relations. It identifies the organizational foundations and principles of labor relations in the emerging new economy in Russia. It reviews the influence of cultural values on how networked labor relations are formed.

The paper uses a multidisciplinary approach to the study of labor relations based on systems theories. The article promotes a new technique for understanding labor relations in an organization based on an extended systems approach, which provides an opportunity to assess the organizational principles of the system of labor relations, to build it in such a way that its different parts interact, respond to changes and send feedback signals, affecting the operation of the system.

The paper discusses ways to solve problems in the field of social and labor relations on both organizational and theoretical levels.
\end{abstract}

Keywords / Mots-clés :

labor relations; economic globalization; network economy; dialogue between labor and capital; an extended systems approach

\section{A NETWORK ECONOMY AND THE POSSIBILITY OF SOCIAL DIALOGUE BETWEEN LABOR AND CAPITAL}

Since the beginning of the 1990s many scholars have written about the formation of a «network economy», using this term to emphasize that the basic quality of the economy of Information Society the organization of production processes in a network, and not the fact that it uses the latest technology. Formation a network economy is characterized by the simultaneous transformation of the economy, labor and employment, labor relations, culture, politics, public institutions, and, ultimately, space and time. The reasons for these changes, as noted by M. Castells and E. Kiseleva, are three independent processes:

(1) the information technology revolution of the 1970s ;

(2) the cultural and social movements of the 1960s - 70s ;

(3) The crisis that led to the restructuring of the two socio-economic systems - capitalism and statism. [Castells, Kiseleva, 2000, p. 24]

A network economy emerged as a result of these three processes.

«A Network Economy» refers to an economy, occurring when the infrastructure, serving the economic performance of a country or group of countries, is based on the use of Internet technologies. At the same time it changes its properties as an economic system as a whole and its individual elements (there are network organizations and coordination mechanisms, there are changes in market institutions, etc.) 
The emergence of new labor relations in a time of globalization and network economy is a difficult and ambiguous phenomenon, and therefore many researchers have expressed serious concern about the fate of labor and social-labor relations. Globalization and computerization of the economy, the rapid dissemination of knowledge, the formation of universal interdependence, has led to the possibility that whereas management operates worldwide, labor is most often tied to place. Many studies describe the deteriorating situation of workers, the atomization of individuals, individualization of labor, and the erosion of social capital. Workers' organizations, established in an era of an industrial economy, are destroyed or weakened. This violates the principle of equality of opportunity to all key players of social and labor relations to represent and protect their interests.

In 1954 Norbert Wiener, the founder of the science of «cybernetics», expressed concern about the «social danger of a new technology». If the first industrial revolution spawned unemployment due to the replacement of manual labor by machines, the second industrial revolution generated by high technology, according to Wiener, should also lead to unemployment as a consequence of the replacement of routine processing work by machines. Wiener feared that the introduction of automatic machines would cause high unemployment affecting many industries and workers, but not industrialists. «However, nothing in the industrial tradition prevents an industrialist from extracting quick profits and retiring before the bankruptcy affects him personally». [Wiener, 1988] Today, according to M. Castells, society once again is split between winners and losers. Work never has played such a significant role in the process of value creation. But workers (regardless of their qualifications) never have been more vulnerable to the organization. Individuals become contract workers for a flexible network whose location is unknown to the network itself. [Castells, 2000]

How does the emergence of a new economy alter the social dialogue between labor and capital? Are we seeing the end of a collective consciousness among workers, amid more individualistic behavior? Are we witnessing tectonic changes in the world economy, in which concepts such as «industrial democracy», «social partnership», «social justice», and «labor rights» disappear? Is the situation so critical? And is there any way out of it?

To summarize the views of scientists dealing with these issues, the meaning will be reduced to the following:

- There is no direct consequence of a network economy in the form of rising unemployment. At the enterprise level a network economy as a result of the introduction of information technologies in the production process leads to a reduction in some jobs. However, on the whole, it leads to job creation at the macro level.

- What will be the result for labor relations from the use of high technology and a network economy in a given country depends on the socio-cultural context. Typically, technological innovation enhances the already established practice of social and labor relations, since technology is only a tool.

- We live in an era of tectonic changes in the economy and society, in an era of restructuring relations between capital and labor «with the help of powerful tools provided by new information technologies and a new organizational form - a network enterprise». [Castells, 2000, p. 43] And this process is not yet completed. However, according to Castells, the worsening situation of workers is not predetermined, by «the informational paradigm».

Probably the kind of labor relations we will have in the future will depend not only on employers but also on employees and their ability to take advantage of the new organizational forms - the network enterprise and, ultimately, on their ability for social learning and self-organization. 


\section{NEW FORMS OF WORK ORGANIZATION AND COMPLEXITY OF LABOR RELATIONS}

In his famous book «The Third Wave» A. Toffler noted that the new economy will consist of unusual for us forms of organization, such as «electronic co-operation», religious and family production teams, nonprofit community work, etc. It may be fundamentally different from the traditional economy, consisting of public and private enterprises, or combinations thereof. [Toffler, 1983, p. 37] There are more and more enterprise networks, new opportunities for getting jobs, remote employment opportunities, a growing number of home-based workers. The actors of labor relations are learning skills to self-organize in networks.

New forms of work organization and labor relations have a number of advantages which are clearly visible in a team: 1) a group of associates, once formed, has fewer disagreements on how to increase in the efficiency of the distribution of functions; 2) they more readily take into account all the views that are exchanged; 3) there is a crystallized formulation of tasks, and an assessment of the importance of tasks which is used to classify tasks in order of importance and priority of execution.

However, not all researchers see only positive consequences of the new forms of work organization and labor relations. Some hold a very skeptical view with regard to the possibilities of retraining and flexible specialization and autonomy of labor and employees. Many are rather critical, pointing out that on the other side of change there is insulation of workers in relation to their colleagues and employers, reducing the importance of collective agreements, the individualization of labor relations, and labor moving from one country to another. There are several disadvantages of the new forms of work organization:

- Where some researchers write about the organizational benefits of decentralization and freedom of labor, it is necessary to emphasize increasing control over the worker;

- There are purely psychological problems that will confront people, such as isolation from the community. The inability to clearly divide home and work can lead to family conflicts;

- Inability to work as a team and feel its stimulating effect, feel the synergy of working together with other team members, the inability to clearly see the results of one's labor, to obtain an estimate of one's work from colleagues, simply to have a live chat - all this leads to demotivation of employees;

- The status of work at home through the internet in modern society is low;

- It was noted that simultaneously with the distribution of jobs and the decentralization of the economy there is a concentration of political power. [Belova, Strizhenko, 2007; Kolosova et al., 2008]

In general, information technologies and a network economy significantly alter and complicate the structure of labor relations. Effective partnerships and cooperation are becoming essential and increasingly important for actors in labor relations. Flexibility and mobility in labor relations is increasing. The intensity and duration of labor communication is varied. There is a constant openness to the organization of labor relations to establish contacts with new partners. Hence, there is a continuing evolution of the structure of relations, which means self-development and self-organization of labor relations. Stability in long-term relationships happens only when such relationships go through a test for effectiveness, when their advantage over existing alternatives of labor relations is established. Establishment of certain bonds in the field of labor and labor relations are increasingly determined by economic expediency. Structures become a part of broader systems interactions and labor relations develop when they are more effective than possible alternatives. The hierarchical relationship of subordination is replaced by a variety of horizontal interactions.

Development of labor relations in the direction of horizontal cooperation significantly increases the adaptability and flexibility of the organization. In an industrial economy with an administrativecommand economic mechanism, trade unions depend on the state, and the interests of workers are subordinated to the public interest. An industrial economy with a market economic mechanism demonstrates contrasting interests of participants in social dialogue. Social dialogue aims at reaching a 
compromise of interests of major participants in labor relations, and compromise - is the recognition of a concession. Accordingly, for the common goal of social dialogue, each participant waives some of his or her interests. In the case of a post-industrial economy with a network economic mechanism there comes into play a completely different mechanism for the coordination of interests: Collaboration is the highest form of cooperation. Collaboration is a «process of formal and informal agreements between autonomous actors, during which joint rules and structures are created and then govern the interaction and ways of working of parties or bind them to solve the problem. These rules and regulations are followed by all the participants, bringing about a win-win». [Katukov et al., 2012, p. 15] Actors in labor relations through intensive interactive dialogue develop a common vision of development and solve current problems.

\section{THE INSTITUTIONAL FRAMEWORK AND THE PRINCIPLES OF LABOR RELATIONS IN A NETWORK ECONOMY}

Self-organization of labor relations may occur differently in the new forms of enterprise organization.

The first basis for a new form of labor relations - organization on a geographical principle, which is due to a convenient location of enterprises in relation to each other, leading to the formation of a specific community and more frequent contacts. This means clusters and industrial districts. An industrial cluster (a set of regionally related industrial, service, financial, natural and communication structures) is the main organizational form of a network economy. As the experience of the Scandinavian countries shows, the organization of labor relations at the level of the cluster or industrial district may be carried out as part of a quadruple helix model. [Katukov et al., 2012, p. 3136] In this case the trade unions are the fourth member of the model: the State (represented by local authorities) - Science - Business. Trade unions can act as Collaboration Institute (American Experience). Collaboration is interactive network communication between self-managing network systems based on horizontal relationships and continuous coordination. It is important that the goal of labor relations, cluster and socio-economic goals of society as a whole must be consistent.

The second basis for a new form of labor relations is a vertical organization of enterprises, which is based on a chain of manufacturers of any product. In this case, the network of labor relations can be formed around this manufacturing process. From our point of view, there can be a classic union, uniting workers of this production chain, or some unions of enterprises in this production chain.

Organization of horizontal network enterprises based on similarity of activities leads to broadening the scope of such structures, which may extend beyond the boundaries of nation states and businesses. Here are the most different forms of collaboration.

Combining the workers may also occur on the basis of membership in a particular profession (professional societies, communities of practice) and on the basis of common interests (for ex., a female union in Japan).

It seems that for the formation and functioning of the networks of labor relations to be effective the following principles should work:

1. Interest by each participant in this collaboration;

2. Independence of participants in labor relations;

3. Possibility of obtaining synergies as a result of communication, expressed in innovative solutions to labor problems;

4. Possibility of coordination and more effective management of relationships with the external environment for the solution of labor problems;

5. Use of network capacity for self-regulation of its activity.

Labor relations in the network, as well as relations in the network organization as a whole, based on cooperation and competition among the parties. Cooperation, aimed at bonding relationships within the network, is centripetal force. Competition, aimed at destructing relationships within the network, is 
centrifugal force. When competitively-cooperative relations are present in a network, it is able to develop. Depending on what prevails, cooperation or competition, a network develops or selfdestructs.

Cooperation among actors of networked labor relations is established on the basis of shared values and common goals. Competition arises from the desire to realize individual goals. Each participant in the network of labor relations is doomed to constant maintenance and updating its image in the eyes of potential partners, have to consider the needs of the partners development, the whole network, strike a balance between his own interests and interests of a network of partnerships development. This, in turn, significantly transforms the objective function of the organization of labor relations, and modifies the motives of their members, which guides their activities. A network organization of labor relations provides a synthesis of self-employed workers and their interdependence and cooperation in achieving common goals. Development of the network organization of interaction of actors of labor relations is inextricably linked with the processes of understanding their interests, goals, motivation, ways to defend their interests, and improving the institutional framework.

\section{THE INFLUENCE OF CULTURE ON FORMING NETWORKED LABOR RELATIONS (RUSSIA AS AN EXAMPLE)}

As pointed out by many researchers, network organization principles are universal. Recognizing the correctness of this conclusion in general, I would like to draw attention to the fact that the forms of implementation of this general principle are different. They depend on the social and cultural environment, the traditions in the field of labor relations, and the traditions in economic life.

More specifically, about Russia, unfortunately, there is a strong tradition of authoritarianism, of vertical organizations. An authoritarian, repressive style of management is the result of the social and economic history of Russia and the established traditions in labor relations. The last three hundred years of Russian history have been years of many reforms and social experiments «from above» in order to organize «lagging» people into a new system of labor relations. Both the czars and later the Soviet regime needed a well-prepared and disciplined work force that would accept very long work days to produce large quantities of goods, while the rational use of these goods for the needs of the people was repeatedly delayed by circumstances. However, during the communist time the Soviet Union used the most advanced technology, techniques and modes of production and, therefore, needed to combine individual initiative and responsibility with old fashioned labor discipline. The organizational methods of the Soviet system combined very old and very new forms of organization. Such a complex socio-economic history was not conducive to the rapid development of network structures of labor relations in Russia.

A researcher of a network economy V. Chekmarev, in particular, writes that the «building block» of the hierarchical structure is the institution, but for a network structure it is a personality. [Chekmarev, 2002, p. 42] Scientists V. Auzan and D. Afrin note, whereas «an institution is based on centralization, vertical subordination, staffing and setting formal goals, a network organization is based on the relative autonomy of parts, outsourcing and risk allocation. Online communities are formed by individuals who formulate their own goals, creating their projects in temporary virtual organizations. If an idea has extended the call, it infected people gathered in clusters. Even if one cluster network is destroyed, others can continue to operate». [Auzan, Afrin, 2012, p. 88]

In Russia the traditional use of an authoritarian style of management led to the suppression of the individual, employees were not encouraged to participate in managerial processes, or it happened in conditions imposed by management. Self-organization of workers was discouraged.

But on the other hand, currently the most organizationally advanced industrial sector in Russia is the information technology market, which in Soviet times simply did not exist. This market has no problems with the so-called «soviet mentality». Until recently, Russia had the world's highest annual rate of growth of the Information Technologies sector - 25-30\% per year. [Dyatlov, Selishcheva, 2009, p. 121]. But it is necessary to note that simply increasing the amount of computer equipment will not 
increase the efficiency of the production process, furthermore, it can contribute to randomization. And the reason for this lag is business thinking, business models, and the organization of social and labor relations for the new technologies. An information society is different from an industrial society not just in technology, but also in social innovations (economic, organizational, administrative and legal). It also includes innovations in social and labor relations: how the production roles of employees are changed in organizations, what kind of organizational environment arises as a result of these changes, whether workers really cooperate in the new organizational environment and develop their creativity and initiative, how the new type of management - management cooperation - develops the new type of social and labor relations. The technical and technological innovations are insufficient without innovations in strategies, processes and business models.

\section{AN EXTENDED SYSTEMS APPROACH TO CHANGE IN LABOR RELATIONS}

The way out of the puzzle which a globalizing economy creates for employees is self-organization. What model of labor relations countries will adopt depends not only on employers but also on employees and their ability to take advantage of the new organizational forms - the networked enterprise, and, ultimately, on their ability to engage in social learning and self-organization.

For the unstable, complex world of a globalizing economy the national labor relations systems must improve their stability and viability due to the growing complexity and instability of the global economy. A relationship between complexity and integrity is needed. Social and cultural factors largely provide this integrity. Ideas, values, beliefs, and goals - in other words the meaning of labor communication - that is what binds people in a society.

The theoretical way out is a multidisciplinary approach to the study of labor relations based on cybernetics and systems theories. I promote a new technique for understanding labor relations in an organization based on an extended systems approach. ${ }^{1}$ (See Medvedeva, 2013, 2014, 2015, 2016) An extended systems approach to labor relations provides an opportunity to assess the organizational principles of the system of social and labor relations, to build it in such a way that its different parts interact, respond to changes and send feedback signals, affecting the operation of the system [9, p. 50]

An extended systems approach to labor relations is based on the assumption that actors are both members of the labor process and also its observers, i.e. the issue of reflexivity is included. Social and cultural values of the actors of social and labor relations - that is the meaning that they are investing in their perception of social and working life, and on which they create individual goals in the organization of work - largely determine their economic choices. Socio-cultural values are also used as a basis for decisions that are reflected in the formation of the relevant rules, standards and values of social and working life. In this sense, the system of labor relations is a reflexive system, and its actors are not just the participants adjusting to changes in the environment, they are able to reconceptualize it. This approach is goal oriented, i.e. it assumes the unity and interdependence of labor processes to the implementation of the meaning of the system of labor relations, expressed in terms of the goal. Therefore the goal is of primary importance. All other components of the system are organized for its implementation. (Fig. 1).

\footnotetext{
${ }^{1}$ An extended systems approach to labor relations is based on a unified approach to understanding biological, cognitive and social phenomena, which is based on a synthesis of modern theories of living systems, including a theory of complex systems. It was described in the book «The Hidden Connections: A Science for Sustainable Living» by the author Fritjof Capra.
} 


\section{SENSE}

\section{CONTENT}

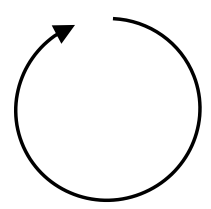

\section{FORM}

\section{PROCESS}

Figure 1. Cycle of change management of labor relations at the enterprise level

1. Sense (meaning) - ideas, beliefs, values, convictions, goals of actors of labor relations.

2. The form of labor relations system is a configuration of relations between the actors, and patterns of their relationships.

3 . The content of the labor relations system - performance and efficiency.

4. The process in the system of labor relations - is social learning, a cognitive process, manifested on the surface as a sequence of actions of actors of labor relations, a set of events describing the change in the system.

To make changes in the system of labor relations, it is necessary to start the mechanism of internal transformation. This can be done by an external impact. However, the outcome is difficult to predict because it depends on the internal recursive processes of the system. Therefore, the process of social learning (cognitive component of social and labor relations system) is of particular importance.

Substantially a cycle of change management in labor relations can be represented as a matrix of «Sense - form - content - process» (Fig. 2).

\section{SENSE: socio-cultural component}

The organization's mission

The organization's goals

Values of the organization's management Values

of employees

Common values

Objectives of the system of social and labor relations

The work ethics, etc.

\section{CONTENT: performance component}

Forms of employment Stability of workplace Wages System to motivate employees Working time and rest time

Conditions and safety Disciplines Social benefits

Distribution of duties Compliance with standards for socially vulnerable groups of employees Labor productivity Fluidity, etc.

\section{FORM: organizational component}

Unions Collective Agreement

Individual contracts Management style

System of employee participation in enterprise management

Mechanism for settling labor conflicts, disputes

Conciliation commission

Administrative methods of regulation of labor relations

Participation of state bodies and local authorities in the regulation of labor relations, etc.

\section{PROCESS: cognitive component}

Retraining

Education

Professional development

Training at the workplace

Work employees on their own projects Employee development

Knowledge Management, etc.

Figure 2. Matrix of "Sense - form - process - content" 
The socio-cultural component of the matrix shows the relation between the values, mission and goals of the organization; how an organization "fits" the environment; what is the purpose of the system of labor relations of the organization; what values lie at its core; whether the system of labor relations contributes to the objectives of the organization; what ideology (and / or social and labor policy) is carried out in the organization; what is the attitude of employees toward work; employee loyalty to the organization; etc.

Organizational component shows the form, the configuration of relations within the organization (hierarchy, subordination, autonomous disunity, competition, network-cooperation), which, ideally, should be optimal for the realization of the sense of the system of labor relations. The reasonableness and consistency of the organization's objectives are important. Furthermore the system stations and mechanisms for the implementation of goals is important, as well as an understanding of how to resolve labor disputes. Depending on the pattern of labor relations in the organization there will be collective agreement, the trade unions, conciliation commissions, etc.

The cognitive component of the matrix shows the process of realization of the meaning and form relationships in the content - the effectiveness of the organization. This occurs through the development of employees as a result of their participation in the production process, the process of improving the organization's activities, managerial decision-making, as well as through learning processes. Accordingly, it is important to understand how the learning process is organized for employees. Is the organization a learning organization?

The content as the performance component reflects the performance and effect of activity for both employees and for the organization as a whole.

The matrix "sense - form - content - process" synthesizes a wealth of information about the labor relations organization. Having this information, we can identify cyclical causal relations in the system of labor relations in organizations, define a type of systems problem, and understand how the system of labor relations "lives" in fact. Using the systems archetypes allocated by outstanding systems researchers helps to do this. Peter Senge, for example, defines 10 system archetypes: Balancing Process with Delay; Limits to Growth; Shifting the Burden; Special Case: Shifting the Burden to the Intervener; Eroding Goals; Escalation; Success to the Successful; Tragedy of the Commons; Fixes that Fail; Growth and Underinvestment. [Senge, p. 378-390] Each of these archetypes is useful in understanding the system of labor relations.

Stages of implementation techniques:

1. Defining the object of analysis: the labor relations system of the enterprise as a whole along with individual departments or business units.

2. Defining criteria to select measures and selecting experts to conduct analyses.

3. Developing by experts the final form of reflection on the results "sense-form-processcontent."

4. Experts fill out the forms agreed upon. There is no limit on the factors used by the experts. Each expert defines a set of factors for each quadrant, which seem to him/her the most important.

5. Preparing the final report on analyses.

6. Using the information in the report to determine the type of problems in labor relations.

7. Using the results from the analysis and the information about types of problems in a strategic planning process.

8. After the planning process, assess whether the planned actions address the problems of labor relations and achieve the stated objectives of the enterprise.

Since the investigated problems are systemic in nature to develop a plan I would recommend to use interactive methods for strategic planning, which allow to attract many participants to solve problem. They represent different points of view, and thus cover the problem from different angles. 


\section{CONCLUSIONS}

1.The changed organization of economic systems from hierarchical to networked, requires a similar change in the organizational principles of labor relations of the new economy, including organizations representing the interests of social and labor rights.

2. Development of a network economy in many countries is accompanied by deterioration of the situation of workers, but studies show that this is the result of the current restructuring of relations between labor and capital in the conditions of globalization and computerization of economy.

3. There is growing interdependence of employee and employer. Dependence of the employer on the employee increases because new technologies need autonomous and educated workers in coordinated teamwork, for cooperative labor relations. Without this, they cannot show their full potential.

4. There is an emerging tendency to form a nucleus of a few well-paid workers, so-called knowledge workers.

5. Computerization of the economy creates opportunities to improve working conditions and enhance economic performance.

6. However, these opportunities are not always used. Some managers are more interested in the possibility of sharply lower production costs. They focus on short-term profits rather than also improving the labor force.

7. Precarious employment is growing (direct hiring on temporary labor contracts; hiring through employment agencies and labor brokers; transfer contracts with other companies; individual employment contracts as covers of the really self-employed workers; abusive duration of probation; employment contract, disguised as training; employment on call / daily employment or "rolling" employee; illegal or part time enforcement; work at home; etc.) Some researches extended this term to the level of society [Bobkov et al, 2014]

8. The role of the self-organization of workers is increased. Social learning processes receive the utmost importance as a mechanism of workers adaptation and development of labor relations in the new conditions. The participants in labor relations are now in conditions where they are forced to learn the principles of network organization and in this way to have the opportunity and responsibility to protect their interests in the new economy.

9. Influence high technology on the problems of labor and labor relations manifests itself differently in different countries. The main reason for this is the different socio-cultural context of technological innovation, which is just a tool to enhance the existing traditions and practices in the labor market.

10. In a time of globalization and formation of the network economy, development of appropriate social and labor relations, growing instability of labor relations, employment instability and other negative phenomena that accompany the development of the new economy, the importance of sociocultural values is increasing as they play a stabilizing role in the process of changes.

11. Traditional formats of labor relations are changing: a gradual transition from full-time to part-time employment, from clearly defined professional positions and responsibilities to blurred content of professional positions; it is acquired uncertainty of the concept of a career and ways to promote it.

12. The terms "workforce" and "labor for wage" are now ineffective because they do not reflect the current realities. Relationships of complicity, co-working, and participation are being developed.

13. The role of co-operative forms of work and labor relations is increased.

14. The employment involves those people who previously could not participate in the labor process, such as the disabled.

15. The networked economy leads to a growing socialization of labor relations, expressed in the increasing role of society in the regulation of labor relations and the importance of social dialogue in the transition from bilateral and trilateral relations in the workplace to multilateralism.

16. New trends of changes in the representation and protection of interests and social and labor rights are emerging: the formation of workers' organizations is operating at the supranational level (for ex., associations of global unions, alliances of trade unions from different countries, European branch federations), expanding the functions of trade unions, creation of new organizations that defend the 
rights of workers, increasing the number of participants in labor relations (for ex., civil society organizations, tripartism - plus ), the commercialization of services to protect the interests of workers (for ex., by lobbying their interests , or design the optimal format of labor relations under order - for a particular project).

\section{RÉFÉRENCES}

Auzan, A. \& Afrin, D. (2001) “Technology against networks”. Expert. 38. (in rus.)

Belova, L. \& Strizhenko, A. (2007) Information Society: transformation of economic relations in a world economy: monograph. Azbuka, Barnaul. (in rus.)

Bobkov, V.N., Veredyuk, O.V., Kolosova, R.P. \& Razumova T.O. (2014) Employment and social precarization in Russia: an introduction to analysis: a monograph. TEIS, Moscow. (in rus.)

Capra, F. (2002) The Hidden Connections. HarperCollins, London.

Dyatlov, S. \& Selishcheva, T. (2009) Regulation of the economy in the transition to innovative development. Monograph. Asterion, St. Petersburg. (in rus.)

Castells, M. (2000) The Information Age: economy, society and culture. State University - Higher School of Economics, Moscow. (in rus.)

Castells, M. \& Kiseleva, E. (2000) "Russia and a network society. Analytical research". The world of Russia. V. IX. - №1. (in rus.)

Chekmarev, V. (2002) Economic space and its network organization. Nekrasov Kostroma State University, Kostroma. (in rus.)

Katukov, D., Malygin, V. \& Smorodinskaya, N. (2012) Institutional environment of a globalized economy: the development of network interactions. Institute of Economy RAS, Moscow. (in rus.)

Kaufman, B.E. (2004) The Global Evolution of Industrial Relations: Events, Ideas and the IIRA. International Labour Organization, Geneva.

Kolosova, R. \& Medvedeva, T. (2015) "Social and labor relations in a network economy". Vestnik $M G U$. Seriya «Economika». 5: 89-104. (in rus.)

Kolosova, R., Razumowa, T. \& Ludanik M. (2008) Forms of employment in an Innovative Economy: Textbook. MAKS Press, Moscow. (in rus.)

Medvedeva, T. (2016) An extended systems approach to social and labor relations in the conditions of globalizing economy. TEIS, Moscow. (in rus.)

Medvedeva, T.A. \& Umpleby, S.A. (2015) "A multi-disciplinary view of social and labor relations: changes in management in the U.S. and Russia as examples". Cybernetics and Systems: An International Journal. 46 (8) : 681-697.

Medvedeva T.A. (2015) "Interpretation of the System of Social and Labour Relations: SFCPTechnique”. Uroven' zhizni naseleniya regionov Rossii. 1(195) : 103-111. (in rus.)

Medvedeva T.A. (2014) "Developing a new type of social and labor relations system in a time of social and economic change". Emergence: Complexity and Organization. 16(4). https://journal.emergentpublications.com/article/15327000160406/

Medvedeva T.A. (2012) "Developing an innovative style of thinking and innovative behavior". Systemic Practice and Action Research: Springer. 25(3) : 261-272.

Nikolaeva T. (2001) Basics of the information economy. Peter, St. Petersburg. (in rus.)

Senge P.M. (1990) The Fifth Discipline: The Art and Practice of the Learning Organization. Doubleday/Currency, N.Y.

Toffler A. (1983) Previews and Premises: An Interview with the Author of «Future Shock» and «The Third Wave». - N.Y.: Morrow, 1983.

Wiener N. (1988) The Human Use of Human Beings: Cybernetics and Society. Da Capo Press, 1988. 